\title{
Break Even Analysis as A Management Tool for Decision Making in Babcock University Water Corporation
}

\author{
ADEDEJI, Elijah Adeyinka and ITUMA, Nneoma Kristen \\ The Federal University of Technology, Akure, Ondo State, Department of Accounting
}

\begin{abstract}
Business and organisational success depends largely on the decision making ability of its management. Decisions regarding forecasting profit and sales in an organisation is often difficult and limited greatly by uncertainty. The study was basically carried out to ascertain if, breakeven analysis is a management tool for decision making. It also investigated, if breakeven analysis can be used to achieve predetermined levels of profit. Hence, the survey research design was adopted, Correlation analysis through the use of SPSS was used to analyse the questionnaires. Also, manual correlation of the cost of production and net income of the case study company, from the review of their four years management accounts was also adopted. From the analysis, there was a positive (though weak) correlation between cost of production and net income and it shows that there is a relationship between both and breakeven is an appropriate tool for management decision making. It was discovered that, breakeven analysis is one of the most reliable methods for management in decision making. Also, changes in any of the constituent elements of the break even such as: output, cost etc. would cause an outright change in all other variables like: level of turnover to breakeven, predetermined level of profit etc. Sensitivity analysis is recommended to be used alongside breakeven analysis in order to be able to easily handle changes in the breakeven point. Breakeven analysis is also best suited for short term decision making, a period of 1-5 years is suitable, as costs change in the long. The importance of proper profit planning and management was also identified.
\end{abstract}

Keywords: Break-even analysis, decision making, uncertainty, profits, sales, cost, break- even point.

DOI: $10.7176 / \mathrm{EJBM} / 12-21-18$

Publication date:July $31^{\text {st }} 2020$

\section{Introduction}

The success of a business depends largely on the ability of the management of such a business to make the right decisions. The need for a decision usually arises in business because a manager is faced with alternative courses of action which he is expected to choose from. In deciding the alternative to choose he will require all relevant information concerning his decision and must have criteria on the basis of which he can choose the best alternative. These decisions are most often about the future, which is quite difficult since it isn't certain and are usually probabilities which may or may not happen. Given the existing risks, competitive conditions and changing levels of activity decision making is even more difficult. In making decisions, a lot has to be taken into consideration such as: costs, volume of production etc. For decision making to be effective, there has to be an in depth understanding of costs, their behaviour on various volumes of production and the resulting effect on profit. (Adeniji, 2001; Drury, 2001)

According to Business Dictionary.com, Profit can be referred to as, the surplus remaining after total costs are deducted from total revenue. It is the basis on which tax is computed and dividend is paid. It is the best known measure of success in an enterprise. It is reflected in reduction in liabilities, increase in assets, and/or increase in owners' equity. It furnishes resources for investing in future operations, and its absence may result in the extinction of a company. It can also be called earnings, gain, or income.

However, accountants' have developed a systematic way of understanding the relationship between decision making and profits so that, decision making can be less tasking, more effective and give a better forecast of the future. It is possible to predict the profit which would emerge at different activity levels or volumes of production 
whether expressed in units or value. This can be done through a method known as "The Break Even Analysis" also known as "Cost Volume Profit Analysis". (Dascher, 2003; Strawser, 2003)

The CVP analysis, often called break-even analysis, is the systematic examination of the interrelationships between selling prices, sales and production volume, costs and profits. It is commonly used tool for decision making. The CVP analysis may be used in setting selling prices, selecting the mix of products to sell, accepting special orders, choosing among alternative marketing strategies and analyzing the effects of cost increases or decreases on profitability of an enterprise. CVP analysis can be considered as indispensable quantitative tool discussed in almost all textbooks relating to business decision-making (Powers, 1987; Harper, 1995; Storey, 1995).

It involves the study of the relationship that exists between costs, level of activity and profit, for the main purpose of decision making and projection of future activities. It is one of the principles used in management accounting to forecast or predict future activity levels in either volume or value. It makes use of the behavioural classification of costs i.e. the classification of costs into fixed and variable elements and can be relied upon for short term planning and decision making. The break-even point is the point where total revenue equals the total costs. An organization neither earns a profit nor incurs a loss at the break-even point; net income at the break even is zero. (Kayode, 2005; Adeniji, 2001)

Break even analysis is undoubtedly the best tool the manager has for discovering the untapped profit potential that may exist in an organization. Break Even analysis can also be used as a valuable tool to identify the extent and magnitude of the economic trouble a division is facing and to help pin point the necessary solution and it helps managers in carrying out sensitivity analysis. Some examples of short run decisions where Break Even Analysis may be useful include: choice of sales mix, pricing policies, multi shift working, special order acceptance etc. (Lucey, 1999; Edmonds, 2000; Enyi, 2012)

\section{Statement of the Problem}

Decision making process involves selecting from a range of possible courses of action that might enable the objectives to be achieved. Before managers can make their choice, they need to compare the likely effects of the options they are considering. If the management of a company concentrates entirely on its present product range and markets, and allows its market shares and profits to decline, there is a danger that the company will be unable to survive in the future. The major issue is selecting the appropriate and best course of action i.e. making the best decision that would yield the greatest profits amongst all the possible alternative courses of action. Selecting the right alternative or making the best decision is a difficult task without having proper information and the right techniques or appropriate evaluation criteria to be considered when making these decisions and if this is not done, it could have an adverse effect on the organization and its profitability.

Hence, break even analysis allows the management to make various types of decisions with respect to establishing selling prices, manufacturing products and planning overall profitability. This study focuses on Break Even analysis and how it can be used by management to make effective decisions especially about the future which will indirectly improve profitability in organizations.

\section{Objectives of the Study}

The importance of adequate decision making cannot be over-emphasized. The main objective or purpose of this research is to determine whether Break Even Analysis is a management tool for decision making. However, the specific objectives of the study are:

-To determine the level of units an organization is expected to produce in order to break-even.

- To determine the level of turnover required by an organization in order to break even.

-To determine if there is a relationship between the break even in sales and a predetermined level of profit.

-To determine if there is a relationship between the level of turnover to break even and the break-even point 


\section{Research Questions}

This research is aimed at providing answers to the following pertinent questions:

-What level of units must an organization produce in order to break even?

-What level of turnover is required by an organization, in order to break even?

-Is there a significant relationship between the break even in sales and a pre-determined level of profit?

-Is there a significant relationship between the level of turnover to break even and the breakeven point?

\section{Research Hypotheses:}

This study shall test the following hypotheses:

\section{Hypothesis 1:}

$\mathrm{H}_{0}$ : There is no significant relationship between the break even in sales and a predetermined level of profit to be achieved by an organization

$\mathrm{H}_{1}$ : There is a significant relationship between the break even in sales and a predetermined level of profit to be achieved by an organization.

\section{Hypothesis 2:}

$\mathrm{H}_{0}$ : There is no significant relationship between the level of turnover to break even and the break-even point.

$\mathrm{H}_{1}$ : There is a significant relationship between the level of turnover to break even and the breakeven point.

\section{Literature Review}

Drury (2005), states that, the Break even analysis or Cost Volume Profit analysis has some underlying assumptions. It is essential that anyone preparing or interpreting information from the analysis, is aware of these underlying assumptions. If these assumptions are not recognized, serious errors may result and incorrect conclusions may be drawn. Some of these important assumptions are discussed below.

All other variables remain constant: It has been assumed that all variables other than the particular one under consideration have remained constant throughout the analysis. In other words, it is assumed that, volume is the only factor that will cause costs and revenue to change. However, changes in other variables such as: production efficiency, sales mix, price levels, production methods etc. will have an important influence on sales revenue and costs. If significant changes in these other variables occur the Break even analysis will be incorrect.

Costs can be accurately split into its Fixed and Variable elements: For the Break Even Analysis to hold there must be an accurate separation of costs into their fixed and variable elements. Even though, in practice it is quite difficult to split semi variable cost into their fixed and variable elements. However some splitting techniques such as: High Low method, Graphical or Scatter Graph method, Linear Regression or Least Squares method and Engineering methods can be used. In other to ensure that, relevant information is used for decision making. 
The analysis applies only to a short term horizon (relevant range only): Break even analysis is based on the relationship between volume and sales revenue, costs and profits in the short term. The short term being is typically, a period of one year. In the short term, the cost of providing a firm's operating capacity are likely to be fixed in relation to changes in activity. Decisions on the firm's intended future potential level of operating capacity will determine the amount of costs to be incurred. These decisions would have been made as part of a long term planning process and can't be easily reversed in the short term.

It is therefore assumed that, in the short term, some costs will be fixed and unaffected by changes in volume whereas other (variable) costs will vary with changes in volume. In the long term, other variables besides volume will cause costs to change.

Complexity related fixed costs /Fixed Costs within a relevant range, do not change: The Break even Analysis assumes that the complexity related costs will remain unchanged. Isiaka \& Abdulrashed (2010) illustrated that, many so called fixed costs vary not with the volume of items manufactured but with the range of items produced (i.e. the complexity of the production process). Complexity-related costs do not normally vary significantly in the short term with the volume of production. If a change in volume does not alter the range of products then it is likely that complexity related fixed costs will not alter, but if volume stays constant and the range of items produced changes then support department fixed costs will eventually change because of the increase or decrease to product complexity. The Break-even analysis does not capture the changes in complexity related costs arising from changes in the range of items produced.

Profits are calculated on a variable costing basis: The analysis assumes that the fixed costs incurred during the period are charged as an expense for that period. Therefore variable costing profit calculations are assumed. However, if absorption costing profit calculations are used, it is necessary to assume that production equal sales for the analysis to predict absorption costing profit. If this isn't done, the inventory levels will change and the fixed overheads allocated for the period will be different from the amount actually incurred during the period.

\section{Concept of Volume in Break Even Analysis}

According to Drury (2012), the term 'volume' is within Break even analysis but this has multiple meanings. Different measures can be used to represent the term. Terms like 'units of output', 'levels of activity' are widely used to connote volume. This raises the question of what constitutes a unit of output or activity; for example, a manufacturing organization like a car manufacturer, volume/ units of output would be the number of cars produced. For service organizations like a hotel, it could be the number of visitors per night etc.

The objective of Break Even Analysis is to establish what will happen to the financial results if a specified level of activity/volume fluctuates. This information is vital to management since, one of the most important variables influencing total sales revenue, total costs and profit is output or volume. For this reason, output is given special attention, since the knowledge of this relationship will enable management identify, the critical output points, such as the level at which neither a profit nor loss will occur i.e. Break-even point. (Drury, 2005)

\section{Concept of Margin of Safety \& Angle of Incidence}

The concept of margin of safety refers to the excess of an organization's expected future sales (in either revenue or units) above the breakeven point. The margin of safety indicates the amount by which sales could drop before profits reach the breakeven point:

Margin of safety in units $=$ Actual or estimated units of activity - Units at breakeven point

Margin of safety in revenue/sales = Actual or estimated revenue - Revenue at breakeven point 
The margin of safety is computed using actual or estimated sales values, depending on the purpose. To evaluate future risk when planning, use estimated sales. To evaluate actual risk when monitoring operations, use actual sales. If the margin of safety is small, managers may put more emphasis on reducing costs and increasing sales to avoid potential losses. A larger margin of safety gives managers greater confidence in making plans such as incurring additional fixed costs. The margin of safety percentage is the margin of safety divided by actual or estimated sales, in either units or revenues. This percentage indicates the extent to which sales can decline before profits become zero. It is expressed as:

Margin of safety percentage in units = Margin of safety in units / Actual or estimated units

Margin of safety percentage in revenues $=$ Margin of safety in revenue / Actual or estimated revenue

Drury (2004), further states that, the margin of safety indicates by how much, sales may decrease before a loss occurs. It can be alternatively expressed in percentage form as:

(Expected sales - Breakeven sales) / Expected Sales

\section{Angle of incidence}

According to managerialblogspot.com, angle of incidence is the angle between the total cost line and the total sales line i.e. it is formed by the intersection of the total cost line and the total sales line on the break even chart. If the angle is large, the firm is said to make profits at high rate and if it is small, the angle is said to make profits at a low rate. Generally, a high angle of incidence and a high margin of safety indicate sound business conditions.

The concept of margin of safety and angle of incidence are illustrated in the diagram below:

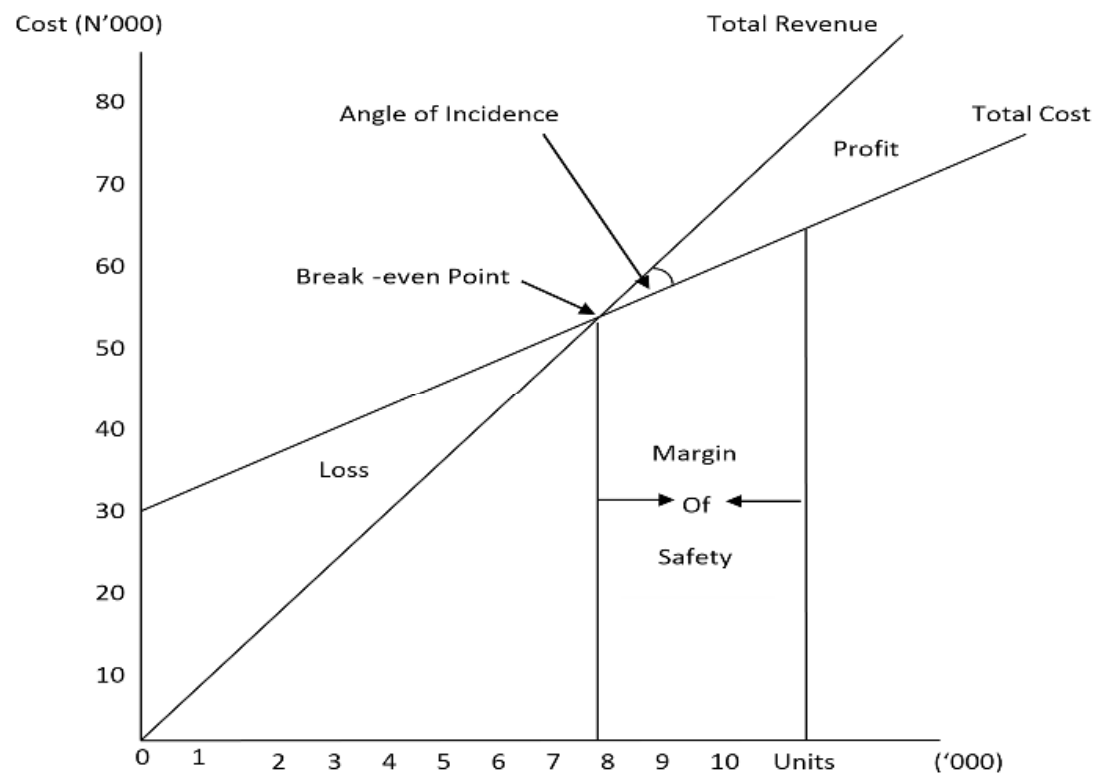




\section{Break-even Chart showing Margin of Safety \& Angle of incidence}

\section{Theory of Break Even Analysis}

According to Hilton (1994), Break even analysis is a technique that summarizes the effects of changes in an organization's volume of activity on its costs, revenues and profit. It can be extended to cover the effect on profit of changes in selling prices, service fees, costs, income tax rates and the organization's mix of products or services. It provides management with a comprehensive overview of the effects on revenues and costs of all kinds of short run financial changes. Although, the word profit appears in the term, it is not confined to profit seeking enterprises alone. Managers in non-profit organizations also routinely use Break even analysis to examine the effect of activity and other short run changes on revenue and costs.

Breakeven point according to Enotes.com Inc (2009), has its origin in the economic concept of the 'Point of Indifference'. From an economic perspective, this point indicates the quantity of some goods at which the decision maker would be indifferent i.e. would be satisfied without reason to celebrate or opine. At this quantity, the costs and benefits are precisely balanced.

The Break-even analysis, often called CVP analysis, is the systematic examination of the interrelationships between selling prices, sales and production volume, costs and profits. It is commonly used tool for decision making. The CVP analysis may be used in setting selling prices, selecting the mix of products to sell, accepting special orders, choosing among alternative marketing strategies and analyzing the effects of cost increases or decreases on profitability of an enterprise. CVP analysis can be considered as an indispensable quantitative tool discussed in almost all textbooks relating to business decision-making (Powers, 1987; Harper, 1995; Storey, 1995).

It has been stated that the break-even point (BEP) is the production volume at which a firm is neither making profit nor loss. Any increase in production from this level results in profit making, while any decrease would result in losses. Industrial enterprises or firms therefore strive to exceed this point so that they can make profit. (Nwachukwu, 2004; Ndaliman, 2007)

Breakeven analysis is one of the most powerful tools that managers have at their command. It helps them understand the inter-relationship between cost, volume and profit in an organization by focusing on the interactions between the following five elements:

$>\quad$ Prices of products
$>\quad$ Polume or level of activity
$>\quad$ Total Fixed Costs
$>\quad$ Mix of products sold.

Adeniji (2004) also stated that, Breakeven/Cost-Volume-Profit analysis represents an application of marginal costing that seeks to study the relationship between cost, volume and profit at different activity levels and can be relied upon for short term planning and decision making. It represents the position where the total cost will equate the total revenue. This concept is heavily relied on the application of the behavioral classification of cost i.e. the major distinction between fixed and variable cost. He also stated that, Break even analysis aims at providing answers to the following undermined questions in an organization. They include: 
How many units an organisation must produce and sell in other to be able to absorb the

total cost of production? (Break -even point in unit)

$\checkmark \quad$ What is the total turnover required by an organisation in order to equate the total cost of production? (Break-even point in sales value)

$\checkmark \quad$ What will be the turn over required by an organisation for the purpose of achieving a predetermined level of profit?

$\checkmark \quad$ Under a predetermined amount of profit, how many units must an organisation produce and sell in order to achieve the desired profit target?

Break-Even Analysis is a valuable tool to identify the extent and magnitude of the economic trouble a division is facing and to help pinpoint the necessary solution. It also helps managers carry out sensitivity analysis by examining the impact of various prices or cost levels on profit. (Hansen \& Mowen, 2003)

Gutierrez and Dalsted (2008), In relation to investment analysis added that, break-even is a useful tool for studying the relationship between fixed costs, variable costs and returns. According to them, a breakeven point defines when an investment will generate a positive return using a given price necessary to cover all costs.

However, break-even analysis is a useful tool for short term planning and decision making and is more relevant where the proposed changes in activity are relatively small so that established cost patterns and relationships are likely to hold good. The amount of fixed costs and the marginal cost per unit are likely to change, hence Break even analysis is unlikely to produce useful guidance. Some examples of typical short run decisions where Breakeven analysis may be useful include: choice of sales mix, pricing policies, multi shift working, special order acceptance etc. (Terry, 2000)

In addition to this, Drury (2012) explained that Break-even analysis is based on the relationship between volume and sales revenue, costs and profits in the short run. This is normally a period of one year, or less, a time in which the output of a firm is likely to be restricted to that available from the current operating capacity. In the short run, there can be increase in outputs but this increase may not be significant e.g. additional supplies of materials and increase in unskilled labour but this may not change the operating capacity significantly. It is important to note that, most of the costs and prices of a firm's products and services would have already been predetermined over a short run period, and the major area of uncertainty will be sales volume. Short run profitability will therefore, be most sensitive to sales volume. Hence, Break even analysis thus highlights the effects of changes in sales volume on the level of profits in the short run.

\section{Methodology}

Survey Research Design also known as Field Research Design is adopted. This method is chosen because, it is the most effective and manageable tool to get facts, opinions, descriptions and other data needed for the study. Both primary and secondary sources were employed, and this is chosen in view of the aim of this research, which is to determine if Break-even analysis is a management tool for decision making. 
The population of the study is the total number of the workers in Babcock University Water Corporation, which is fifty-five (55). The organisation is divided into the following departments: Bottling, Nylon, Stores, Packaging, Distribution and an Accounts department which is Central to the entire Babcock University Ventures not only the Water Corporation.

The sample size would be determined statistically, by using the Yaro Yamani formula as stated below:

$$
n=\frac{N}{1+N(e)^{2}}
$$

Where:

$\mathrm{n}$ is Sample size N is Population

$=55 \mathrm{e}$ is Margin of Error $=0.05$

Hence,

$n=\frac{55}{1+55(0.05)^{2}}$

$n=\frac{55}{1.1375}$

$\mathrm{n}=48.3516$

$\approx 48$

Hence, the sample size is forty-eight (48).

The data analysis method employed for the purpose of this research is the Correlation Analysis, specifically The Correlation Coefficient. It is a descriptive statistical method that measures association/relationship. It is to be computed both manually and using the Statistical Package for Social Sciences (SPSS).

The correlation coefficient is also known as Pearson Product Moment Correlation Coefficient (PPMCC). It was originated by Karl Pearson and is used to show the relationship between two sets of interval scaled or ratio-scaled variables. It is simply a measure of the strength of the linear relationship between two sets of variables. (Choo \& Tan, 2011)

For the sake of this study, the Correlation Coefficient is employed because; of the need to establish whether there is a relationship or not between the cost of production and profitability of the organisation (Babcock University Water Corporation, a subsidiary of Babcock University Ventures). Since, break-even analysis leads to optimization and profitability, the profitability of the organisation, ascertained through its net income, is then correlated with its cost of production. 
TABLE 1.1: TOTAL ANALYSIS OF QUESTIONNAIRE

\begin{tabular}{|l|c|c|}
\multicolumn{1}{c}{$\begin{array}{c}\text { NUMBER OF } \\
\text { QUESTIONNAIRES }\end{array}$} & PERCENTAGE OF \\
& & \multicolumn{1}{c|}{ DISTRIBUTION } \\
\hline ADMINISTERED & 48 & $100 \%$ \\
\hline COLLECTED & 48 & $100 \%$ \\
\hline
\end{tabular}

Source: Field Survey, February 2017.

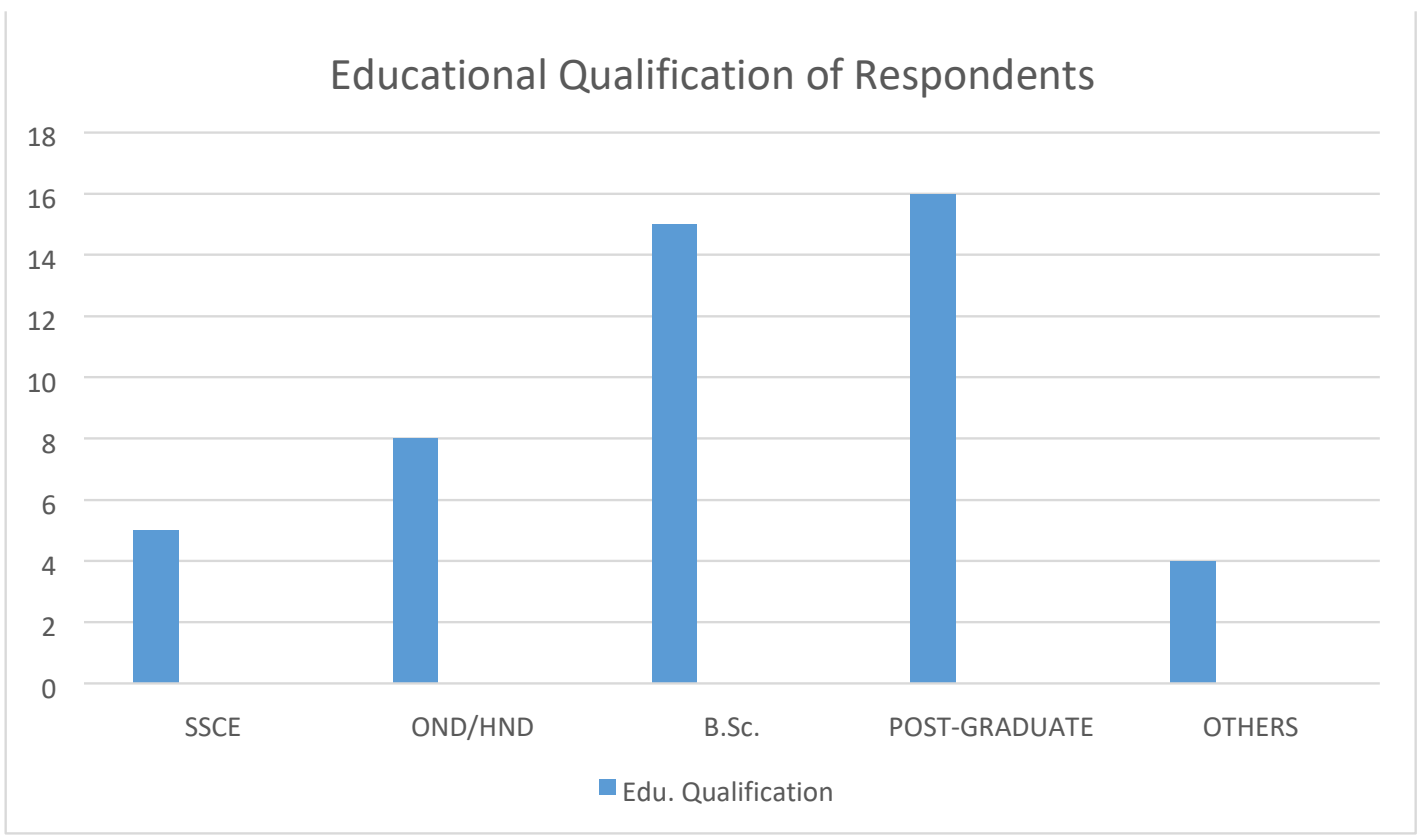

Figure 1.1: Chart showing Educational Qualification of Respondents Source: Field Survey, February 2017.

ANALYSIS: Out of the total respondents, 5 had SSCE Qualification, 8 had OND/HND Qualification, 15 had B.Sc. Qualification, 16 had Post- Graduate Qualification and 4 had other qualifications apart from the options. 


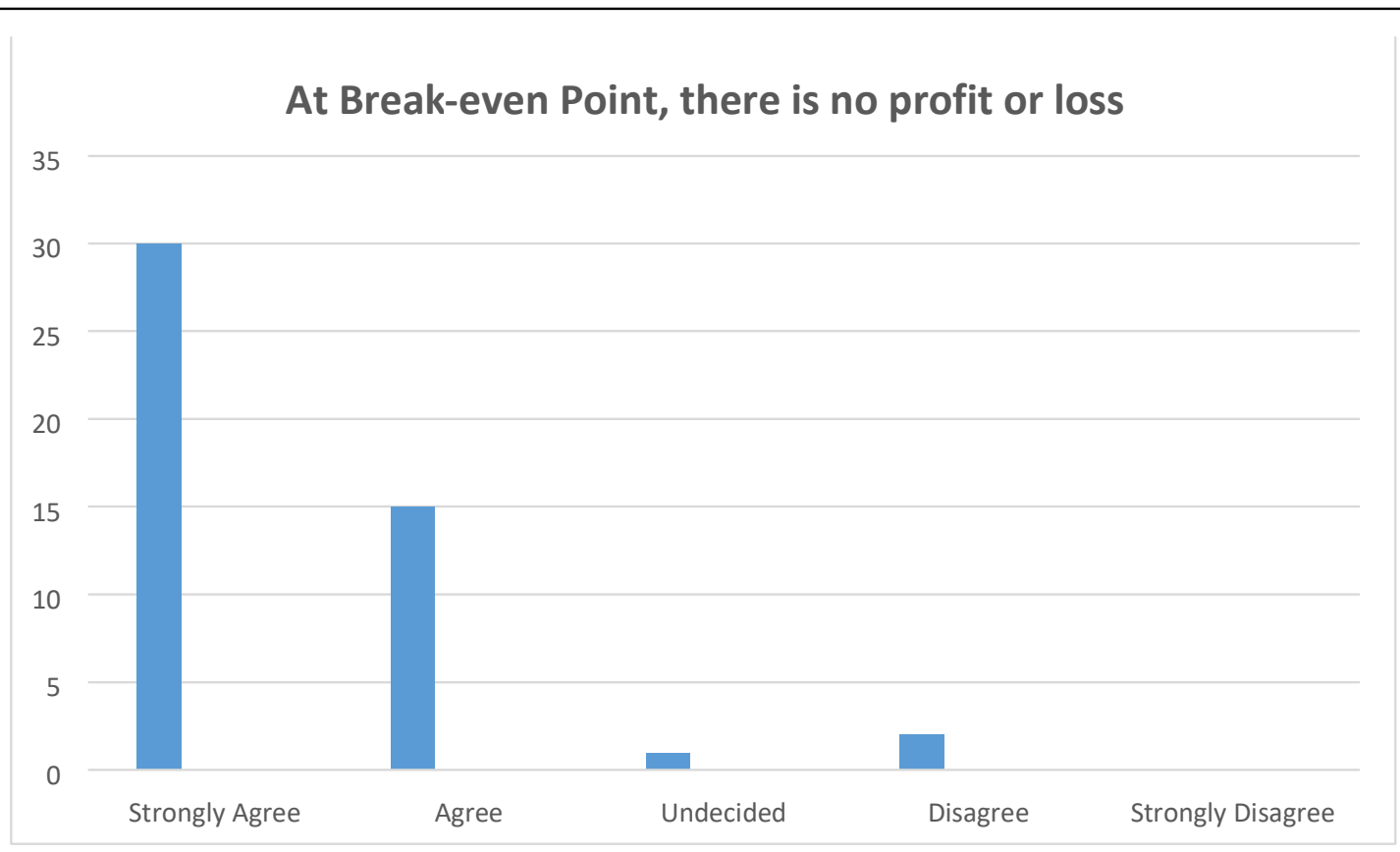

Figure 1.2: Bar Chart showing response to Question 9

Source: Field Survey 2017

ANALYSIS: 30 respondents Strongly Agree that, at Break-even point, there is no profit or loss, 15 respondents Agree, 1 respondent is Undecided, 2 respondents Disagree. This authenticates the fact that at, Break-even point there is no profit or loss.

\section{The use of Break-even analysis does not ensure profitability in an organisation}

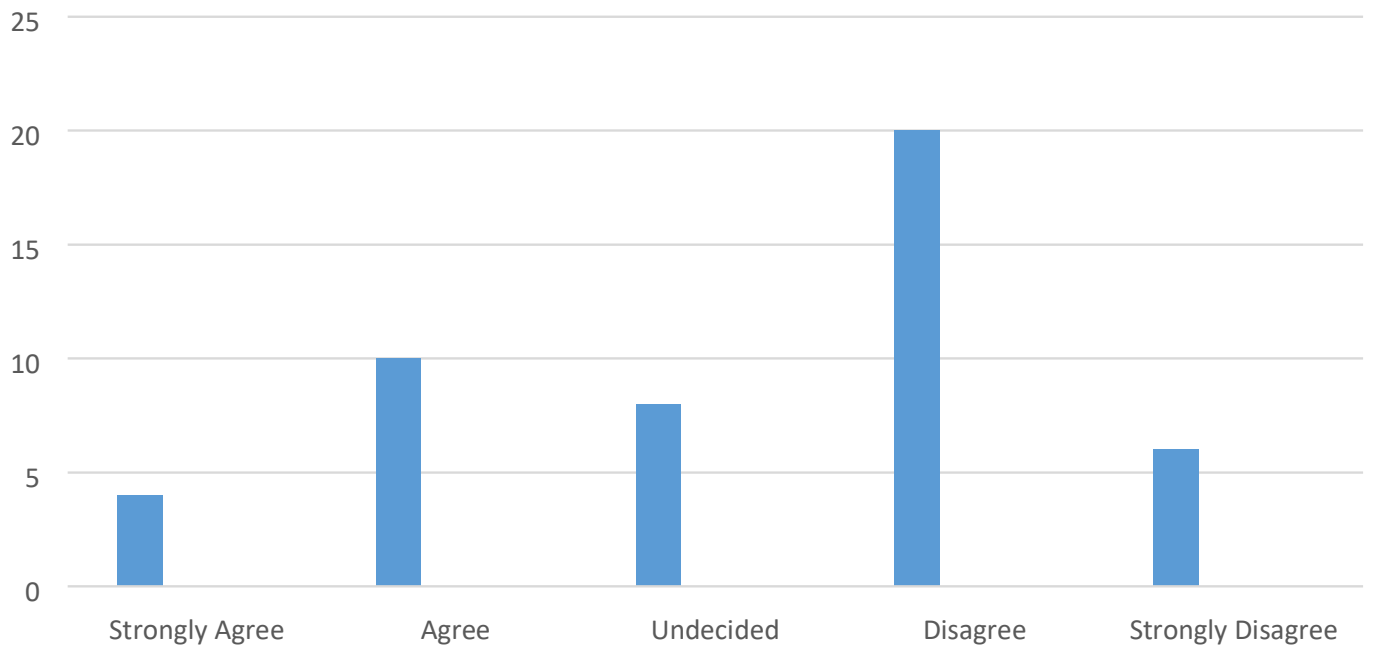

Figure 1.3: Bar Chart showing response to Question 10 
Source: Field Survey, February 2017

ANALYSIS: 4 respondents strongly agree that, the use of Breakeven does not ensure profitability in an organisation. 10 respondents agree, 8 respondents are Undecided, 20 respondents disagree and 6 strongly disagree. Hence, it is concluded that, the use of breakeven analysis ensures Profitability.

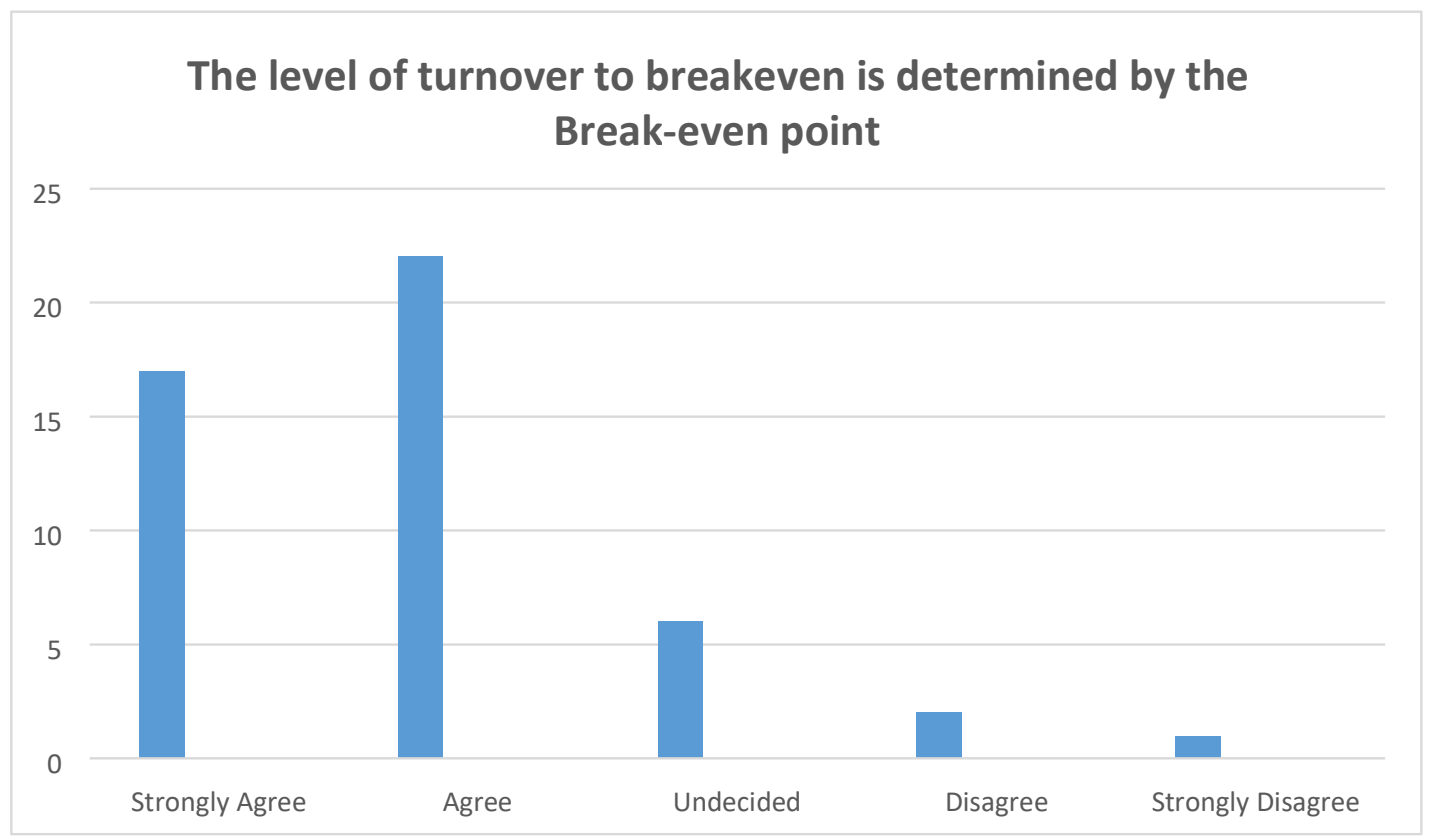

Figure 1.4: Bar Chart showing response to question 11

Source: Field Survey, February 2017.

ANALYSIS: 17 respondents strongly agree that, the level of turnover to break-even is determined by the breakeven point. 22 respondents agree, 6 are Undecided, 2 respondents agree and 1 strongly disagrees. Hence, it is concluded that, the level of turnover to Break even is determined by the breakeven point. 


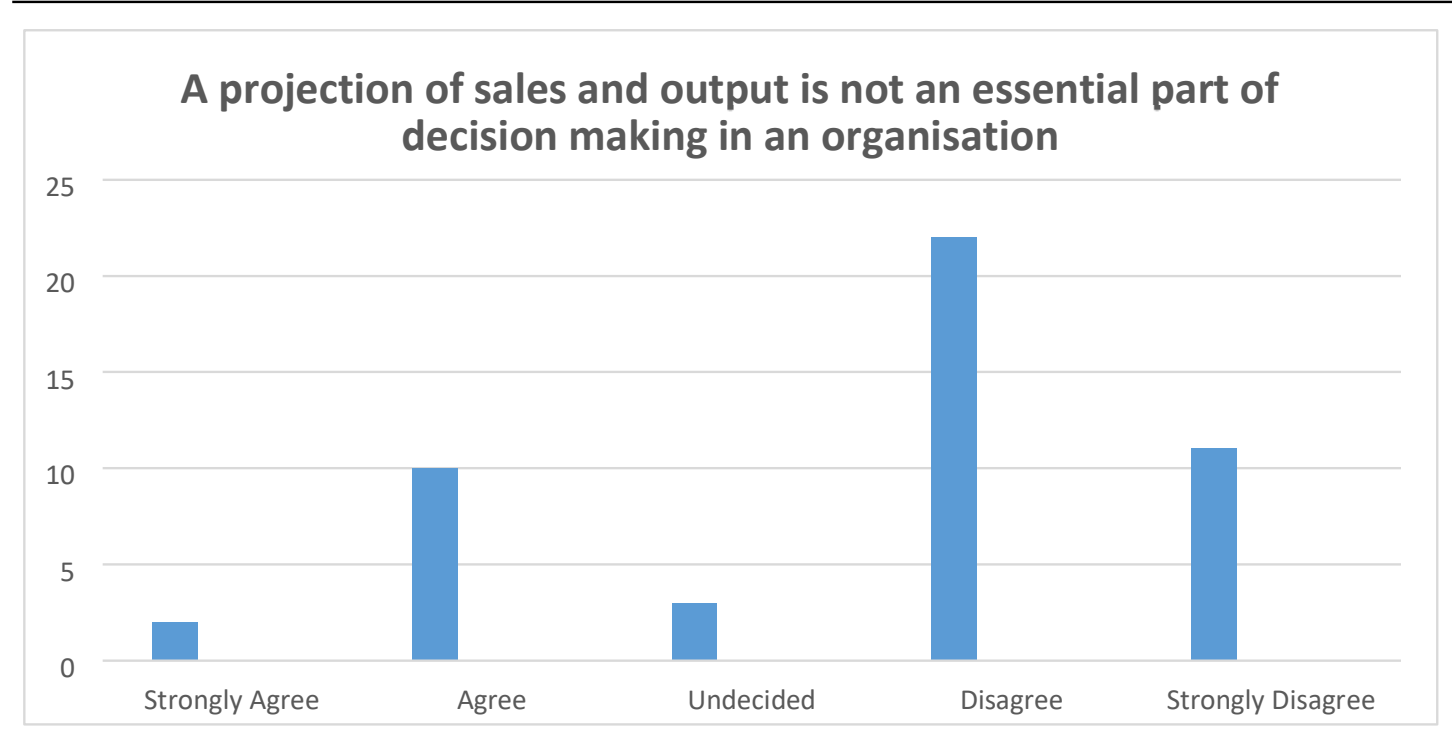

Figure 1.5: Bar Chart showing response to question 12

Source: Field Survey 2017

ANALYSIS: 2 respondents strongly agree that, a projection of sales and output is not an essential part of decision making in an organisation. 10 respondents agree, 3 are Undecided, 22 respondents disagree \& 11 strongly disagree. It is concluded that, a projection of sales \& output is an essential part of decision making in an organisation.

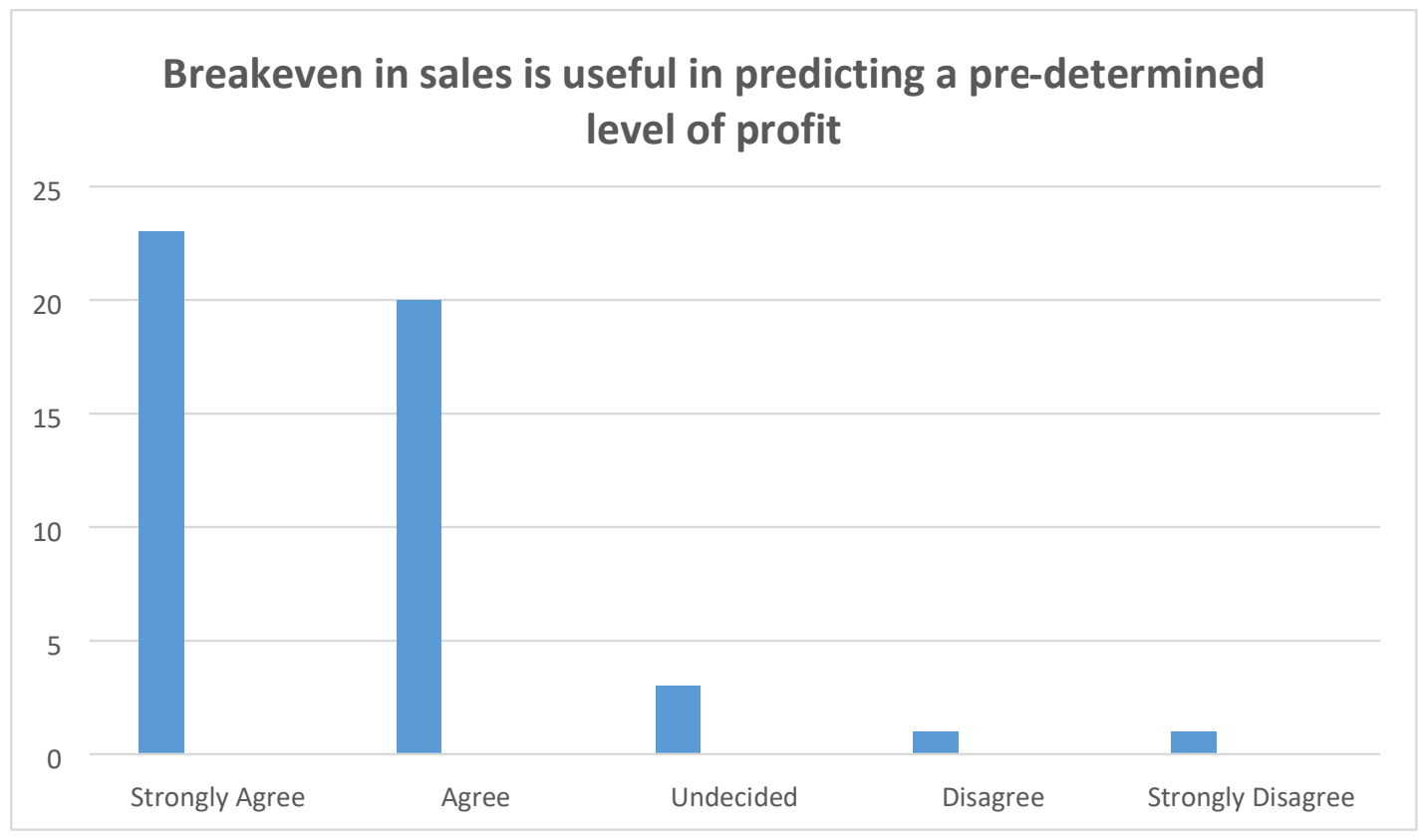

Figure 1.6: Bar Chart showing response to question 13

Source: Field Survey, February 2017 
ANALYSIS: 23 respondents strongly agree that, Break even in sales is useful in predicting a predetermined level of profits. 20 respondents agree, 3 are undecided, 1 respondent disagrees and 1strongly disagrees. It is concluded that, Break even in sales is useful in predicting a predetermined level of profit.

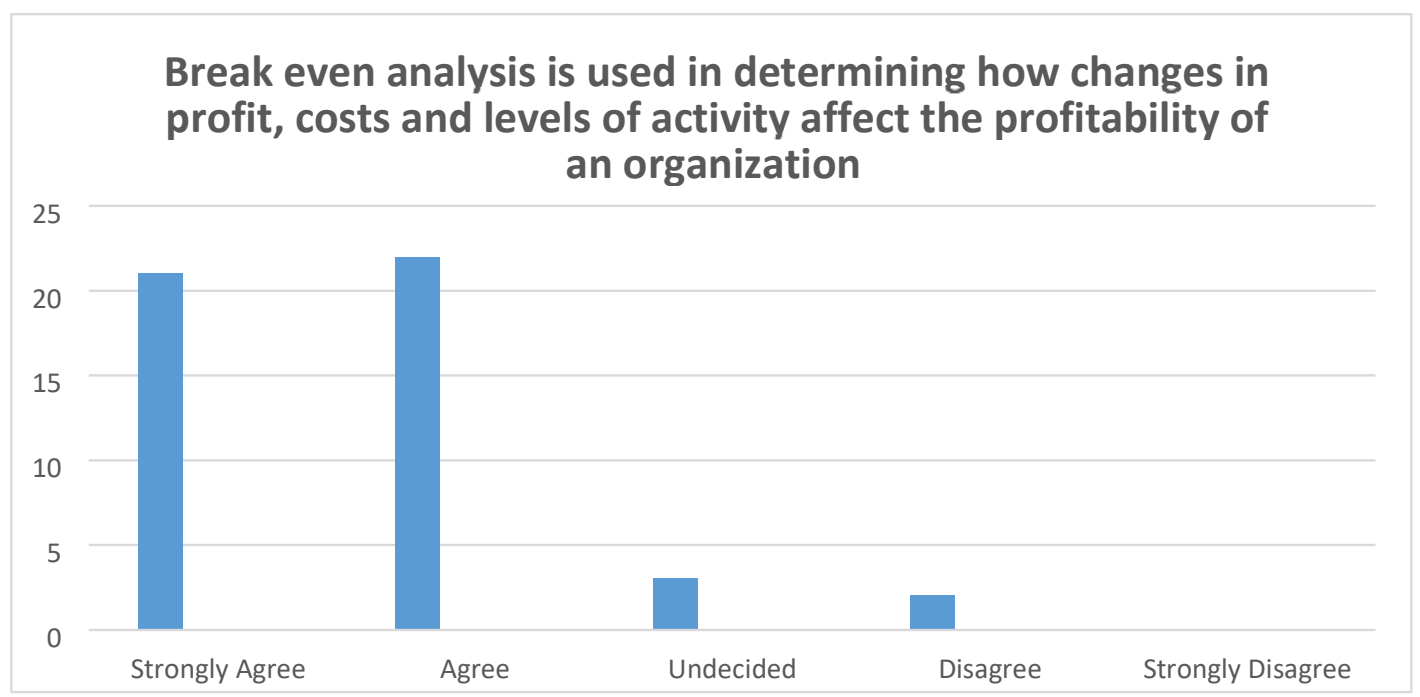

Figure 1.7: Bar Chart showing response to question 14

Source: Field Survey, February 2017

ANALYSIS: 21 respondents strongly agree that, Break even analysis is used in determining how changes in profit, costs and levels of activity affect the profitability of an organization. 22 respondents agree, 3 are undecided \& 2 respondents disagree. Hence, it is concluded that, Break even analysis is used in determining how changes in profit, costs and levels of activity affect the profitability of an organization.

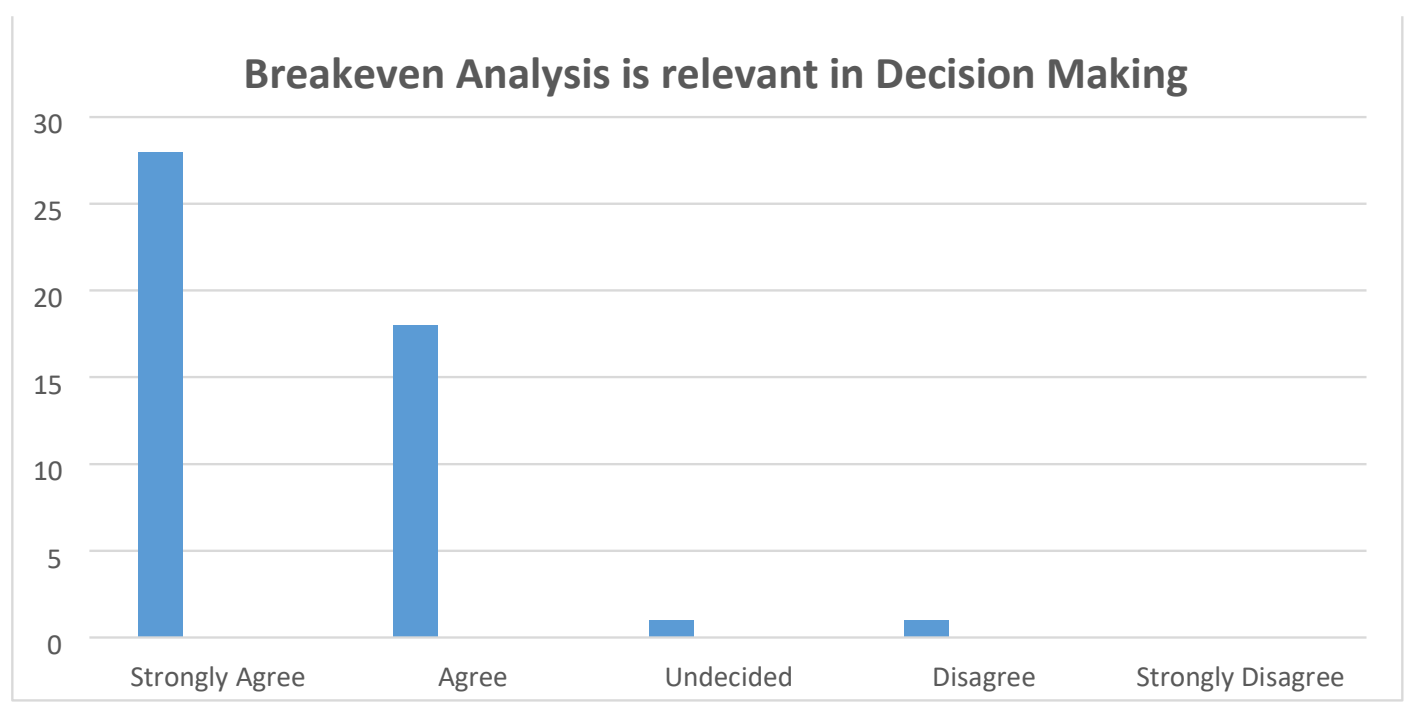

Figure 1.8: Bar Chart showing response to question 15 Source: Field Survey, February 2017. 
ANALYSIS: 28 respondents strongly agree that Breakeven is relevant in decision making, 18 agree, 1 is undecided \& 1 respondent disagrees. In conclusion, Breakeven is relevant in decision making.

Test of Hypotheses

Here, both hypothesis will be tested.

\section{Test of Hypothesis 1 Hypothesis}

$\mathrm{H}_{0}$ : There is no significant relationship between the break even in sales and a predetermined level of profit to be achieved by an organization

$\mathrm{H}_{1}$ : There is a significant relationship between the break even in sales and a predetermined level of profit to be achieved by an organization.

\section{Test of Hypothesis 1 using SPSS:}

\section{Correlations}

\begin{tabular}{|c|c|c|c|}
\hline & & $\begin{array}{c}\text { VAR000 } \\
01\end{array}$ & $\begin{array}{c}\text { VAR000 } \\
02\end{array}$ \\
\hline $\begin{array}{l}\text { Pearson } \\
\text { Correlation }\end{array}$ & $\begin{array}{l}\text { VAR000 } \\
01\end{array}$ & 1.000 & .910 \\
\hline & $\begin{array}{l}\text { VAR000 } \\
02\end{array}$ & .910 & 1.000 \\
\hline Sig. (1-tailed) & $\begin{array}{l}\text { VAR000 } \\
01\end{array}$ & & .016 \\
\hline $\mathrm{N}$ & $\begin{array}{l}\text { VAR000 } \\
02 \\
\text { VAR000 } \\
01\end{array}$ & $\begin{array}{r}.016 \\
5\end{array}$ & 5 \\
\hline & $\begin{array}{l}\text { VAR000 } \\
02\end{array}$ & 5 & 5 \\
\hline
\end{tabular}

Source: SPSS 15 Evaluation, April 2017 


\section{Coefficients (a)}

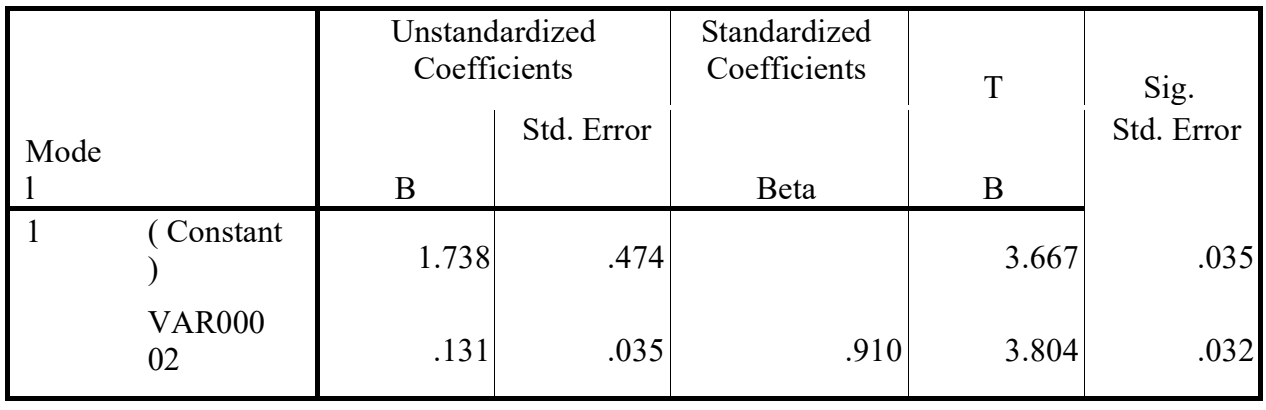

Source: SPSS 15 Evaluation, April 2017.

\section{ANALYSIS:}

$\mathrm{PPMC}=0.910$

$\mathrm{T}_{\text {calc }}=3.804$

$\mathrm{T}_{\mathrm{tab}}=1.679$

Decision Rule: If $\mathrm{T}$ tab $>\mathrm{T}$ calc - Reject $\mathrm{H}_{1}$ and Accept $\mathrm{H}_{0}$

If $\mathrm{T}$ tab $<\mathrm{T}$ calc - Accept $\mathrm{H}_{1}$ and Reject $\mathrm{H}_{0}$

$1.679<3.804-$ Accept $\mathrm{H}_{1}$ and Reject $\mathrm{H}_{0}$

Hence, there is a significant relationship between the break even in sales and a predetermined level of profit to be achieved by an organization.

\section{Test of Hypothesis 2:}

$\mathrm{H}_{0}$ : There is no significant relationship between the level of turnover to break even and the break-even point.

$\mathrm{H}_{1}$ : There is a significant relationship between the level of turnover to break even and the breakeven point. 
Test of Hypothesis 2 using SPSS:

\section{Correlations}

\begin{tabular}{|c|c|c|c|}
\hline $\begin{array}{l}\text { Correlation } \\
\text { Sig. (1-tailed) }\end{array}$ & $\begin{array}{l}01 \\
\text { VAR000 } \\
02 \\
\text { VAR000 } \\
01 \\
\text { VAR000 } \\
02 \\
\text { VAR000 } \\
01 \\
\text { VAR000 } \\
02\end{array}$ & $\begin{array}{r}.875 \\
. \\
.026 \\
5 \\
5\end{array}$ & 1.000 .026 \\
\hline & & $\begin{array}{c}\text { VAR000 } \\
01\end{array}$ & $\begin{array}{c}\text { VAR000 } \\
02\end{array}$ \\
\hline Pearson & VAR000 & 1.000 & .875 \\
\hline
\end{tabular}

Source: SPSS 15 Evaluation, April 2014.

\section{Coefficients (a)}

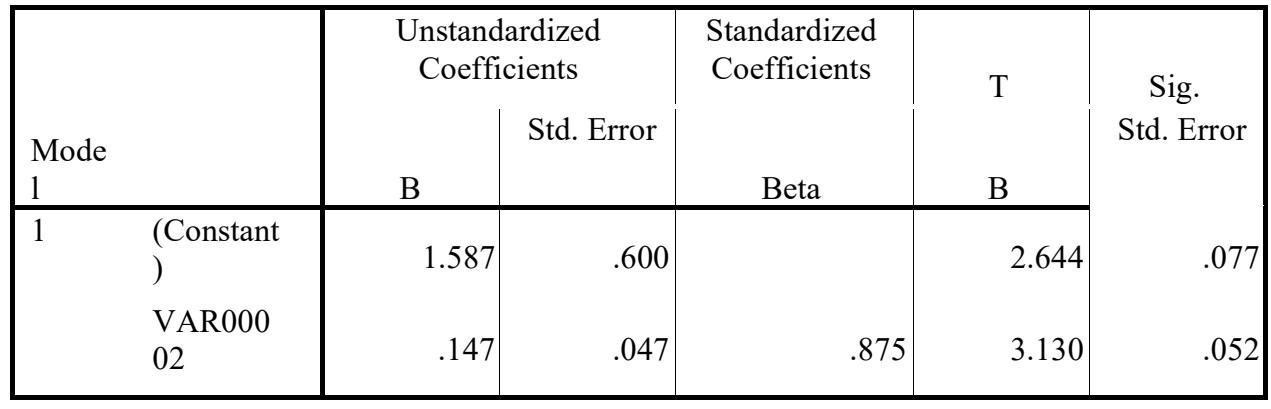

SPSS 15 Evaluation, April 2017.

\section{ANALYSIS:}

$\mathrm{PPMC}=0.875$

$\mathrm{T}_{\text {calc }}=3.130$

$\mathrm{T}_{\mathrm{tab}}=1.679$ 
Decision Rule: If $\mathrm{T}$ tab $>\mathrm{T}$ calc - Reject $\mathrm{H}_{1}$ and Accept $\mathrm{H}_{0} \quad$ If $\mathrm{T}$ tab $<\mathrm{T}$ calc - Accept $\mathrm{H}_{1}$ and Reject $\mathrm{H}_{0}$

$1.679<3.130-$ Accept $\mathrm{H}_{1}$ and Reject $\mathrm{H}_{0}$.

Hence, there is a significant relationship between the level of turnover to break even and the break-even point.

\section{Analysis and Correlation of Secondary Data}

The major objective of this study is to determine if, Break-even is a management tool for decision making. Hence, Breakeven is the independent variable ( $\mathrm{x}$ ) and decision making the dependent variable. $(\mathrm{y})$

For the purpose of this study, Break-even will be represented by the Cost of Production and

Decision Making by the Net income of the Case study Company, which is Babcock University Water Corporation (A subsidiary of Babcock University Ventures) for a period of 2013 to 2016. (4years)

Since, it is believed that, Break-even Analysis ensures Profitability, the Net income will be correlated with the Cost of Production, in order to determine, if there is a relationship and the strength of the established relationship between both elements. (Cost of Production \& Net income).

PPMC:

$$
r=\frac{n\left(\sum X Y\right)-\left(\sum X\right)\left(\sum Y\right)}{\sqrt{\left[n\left(\sum_{X}^{2}\right)-\left(\sum_{X}\right)^{2}\right]\left[n\left(\sum_{Y}^{2}\right)-\left(\sum_{Y}\right)^{2}\right]}}
$$

Where:

$\mathrm{n}$ is the number of paired observations.

$\sum y_{i}$ is the $\mathrm{X}$ variable summed.

$\sum Y$ is the $\mathrm{Y}$ variable summed.

$\mathrm{X}^{2}$ is the $\mathrm{X}$ variable squared and the squares summed.

$(\Sigma X)^{2}$ is the $\mathrm{X}$ variable summed and the sum squared.

$\sum \mathrm{Y}^{2}$ is the $\mathrm{Y}$ variable squared and the squares summed.

$\left(\sum \mathrm{Y}\right)^{2}$ is the $\mathrm{Y}$ variable summed and the sum squared. 
$\sum X Y$ is the products of $\mathrm{X}$ and $\mathrm{Y}$.

$\mathrm{X}$ is the cost of production.

$\mathrm{Y}$ is the net income.

$\mathrm{r}$ is the correlation coefficient.

TABLE: 1.2: PPMC Table for Secondary Data Analysis

\begin{tabular}{|r|r|r|}
\hline YEAR & X - COST OF PRODUCTION & \multicolumn{1}{|c|}{ Y NET INCOME } \\
\hline $\mathbf{2 0 1 3}$ & $27,417,906.43$ & $9,808,101.56$ \\
\hline $\mathbf{2 0 1 4}$ & $32,045,306.50$ & $1,877,135.62$ \\
\hline $\mathbf{2 0 1 6}$ & $37,244,177.00$ & $28,073,474.84$ \\
\hline TOTAL & $49,622,648.96$ & $15,558,631.75$ \\
\hline & $\mathbf{1 4 6 , 3 3 0 , 0 3 8 . 8 9}$ & $\mathbf{5 5 , 3 1 7 , 3 4 3 . 7 7}$ \\
\hline
\end{tabular}

Source: Management Accounts of Babcock University Water Corporation, 2013-2016

TABLE 1.3: PPMC Table for Secondary Data Analysis cont.

\begin{tabular}{|r|r|r|r|}
\hline \multicolumn{1}{|c|}{ YEAR } & \multicolumn{1}{|c|}{$\mathrm{X}^{2}$} & \multicolumn{1}{c|}{$\mathrm{Y}^{2}$} & \multicolumn{1}{|c|}{ XY } \\
\hline $\mathbf{2 0 1 3}$ & $751,741,593,004,235.00$ & $96,198,856,211,274.40$ & $268,917,610,828,017.00$ \\
\hline $\mathbf{2 0 1 4}$ & $1,026,901,668,678,940.00$ & $3,523,638,135,872.78$ & $60,153,386,284,967.50$ \\
\hline $\mathbf{2 0 1 5}$ & $1,387,128,720,407,330.00$ & $788,119,989,592,113.00$ & $1,045,573,465,946,010.00$ \\
\hline $\mathbf{2 0 1 6}$ & $2,462,407,289,807,390.00$ & $242,071,021,932,108.00$ & $772,060,521,628,160.00$ \\
\hline TOTAL & $\mathbf{5 , 6 2 8 , 1 7 9 , 2 7 1 , 8 9 7 , 9 0 0 . 0 0}$ & $\mathbf{1 , 1 2 9 , 9 1 3 , 5 0 5 , 8 7 1 , 3 7 0 . 0 0}$ & $\mathbf{2 , 1 4 6 , 7 0 4 , 9 8 4 , 6 8 7 , 1 5 0 . 0 0}$ \\
\hline
\end{tabular}

Source: Author's Computation, 2017.

$$
r=\frac{492,230,873,593,008}{1,267,263,076,383,030}
$$


$r=0.388420434$

$r=0.3884$

\section{Using SPSS,}

\section{Correlation}

\begin{tabular}{|ll|r|r|}
\hline & & \multicolumn{1}{|c|}{$\begin{array}{c}\text { Cost of } \\
\text { Production }\end{array}$} & Net Income \\
\hline VAR000 & Pearson & 1 & .388 \\
& Correlation & & .612 \\
& Sig. (2-tailed) & & 4 \\
& N & 4 & \\
& & & \\
VAR000 & Pearson & .388 & 1 \\
02 & Correlation & .612 & \\
& Sig. (2-tailed) & 4 & 4 \\
& N & & \\
\hline
\end{tabular}

Source: SPSS 15 Evaluation, April 2017

\section{Coefficients(a)}

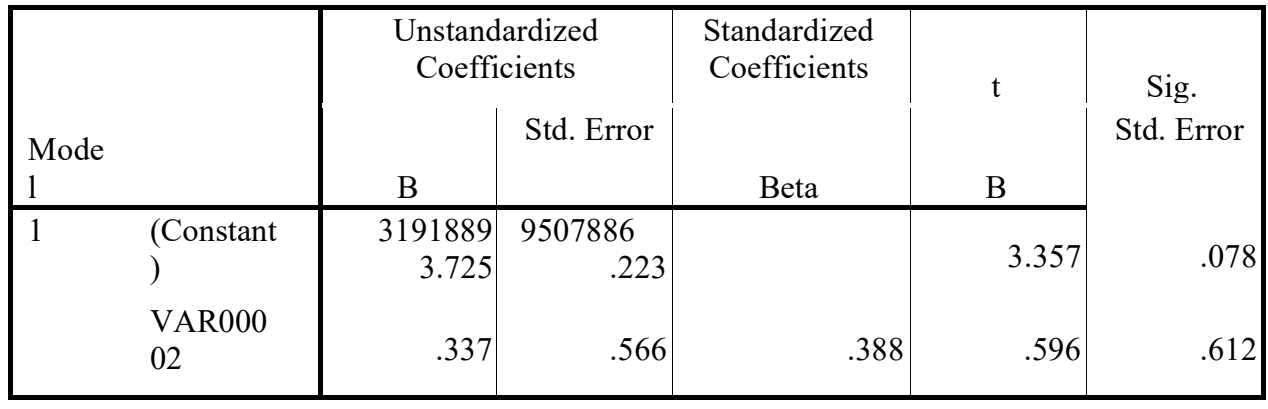

Source: SPSS 15 Evaluation, April 2017

$\mathrm{PPMC}=0.388$

$\mathrm{T}$ calc $=3.357$

$\mathrm{T}$ tab $=2.920$

$\mathrm{T}$ tab $<\mathrm{T}$ calc, Hence $\mathrm{r}$ is validated.

INTERPRETATION: There is a weak positive correlation between Breakeven Analysis and Decision Making. Also, using the $t$ test, the correlation coefficient $r$ has been validated, and it can be concluded that there is a 
relationship between Break even Analysis and Decision making i.e. Break even analysis is a tool for decision making.

This also supports the facts already established under the testing of the hypothesis by the primary data. I.e. there is a significant relationship between the break even in sales and a predetermined level of profit to be achieved by an organization $\&$ there is also a significant relationship between the level of turnover to break even and the breakeven point.

\section{Discussion of Findings}

In the course of carrying out this study, different findings were made. They will be discussed in detail below.

The study investigated basically, if there is a relationship between the break even in sales and a predetermined level of profit. i.e. if Break even analysis, can be used to achieve or arrive at an appropriate predetermined level of profit, that can be relied upon, for the sake of decision making and profit planning.

It was discovered that, Break even analysis is one of the most reliable methods to arrive at a pre-determined level of profit, to be used in decision making and profit planning process of an organisation. The study also revealed, the importance of profit, proper profit planning and management in an organisation. Profit is one of the commonest ways of measuring success in an enterprise, with exceptions to when an organisation declares only notional profit and is not liquid. Profit provides the resources for investment in future operations, and its absence may result in the extinction of a company.

Hence, profit planning or profit decisions should be included as part of the Basic Financial Management and Investment decisions of a business i.e. Investment Decisions, Financial Decisions, Liquidity Decisions, Dividend \& Retention Decisions and Profit Decisions; unlike, the initial work done by Pandey, Omolehinwa and others that highlighted all other decisions except the Profit Decisions. It clearly supports the work done by Akintoye in 2004, which included Profit decisions as part of the Basic Financial Management and Investment Decisions.

The study also investigated whether, the level of sales to break even, which is often used in decision making and planning, is affected by the break-even point. i.e. to know, if any changes in the break-even point would affect the level of sales to break even.

It was discovered, that changes in the break-even point would result in direct changes to the level of turnover to break even. It was also discovered that, changes in volume or costs or other constituents that make up the Breakeven point, would cause a significant change in the Breakeven point, which would in turn change other variables like Break even in sales, predetermined level of profit etc. Any significant change has a ripple or wave like effect, it goes through to almost if not all variables immediately, which means the earlier analysis done is wrong and would result in, inaccurate decisions.

Furthermore, the time factor is very important in Break-even analysis. It was discovered that, Break-even is best suited for short term decision making, because overtime i.e. in the long term, costs change. This means that, some costs that were variable may become fixed, or may cease to exist. For example, rent on a building was variable in the first five years of production, but the building was acquired in the sixth year. Hence, from the sixth year, the variable cost of rent ceases and the cost of the building becomes a fixed cost, which is a sunk cost. On the other hand, fixed costs may increase or decrease or no longer exist. i.e. in the case of disposal of an asset, or acquisition of new machines for production etc. An example of a fixed cost becoming variable is, when the leasehold on a building ends, and the organisation decides not to renew this leasehold but would rather pay rent on it instead.

It should also be noted, in ascertaining the level of units and level of turnover to breakeven (i.e. determining the Break even in units and sales), different methods can be used. Either, the Contribution Approach, Equation Approach, Graphical Approach etc. However, the different methods revealed by this study all yield the same results 
regardless of which is applied for decision making. The concerned organisation has to choose which to method or approach to adopt.

\section{Conclusion and Recommendations}

As stated earlier in this study, selecting the right alternative or making the best decision is a difficult task without having proper information and the right techniques or appropriate evaluation criteria to be considered when making these decisions.

In this light, it was discovered in the process of this study that, Break-even analysis is one of the most reliable and important tools or techniques to be used by management to aid the decision making process of an organisation and ultimately ensure profitability.

In order to ensure adequate decision making and profitability in organisations, with the use of breakeven analysis, the following recommendations are made.

1. Selling prices should be planned in a manner that, covers all costs and expenses first i.e. breakeven first, and then make profit afterwards. Hence, the breakeven point/price is the minimum selling price, and any attempt to sell below it, will not result in a profit, but a loss instead. In order to ensure profitability, organisations should:

Produce/Sell

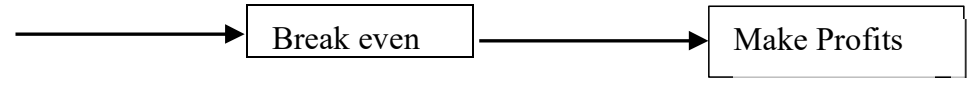

The link above shows that, there is no way, organisations can make profits without breaking even. Hence, breaking even, should be the first priority and then profits follow successively.

2. Use of Sensitivity Analysis, together with Break-even analysis: Change is a constant factor in everything. As discussed earlier, a single change in any variable often has a wave like or ripple effect through to other variables. E.g. changes in variables such as: volume or output, costs etc. result in changes in the Break-even point which in turn affects the Break in sales, predetermined level of profit etc. Hence, sensitivity analysis enables managers examine how a result or variable will change if the original predicted data are not achieved or if an underlying assumption changes. In the context of Breakeven analysis, sensitivity analysis helps to examine how the breakeven point changes if the predicted data for selling price, variable cost per unit, fixed costs, or units sold are not achieved. It gives interval estimates not just point estimates, hence any change is handled easily, especially if it is within the interval or range given. 
3. Also, appropriate care should be taken in determining the breakeven point, especially for forecasts which involve the use of past or historical information to predict figures to be used in decision making. The information should be reliable, as wrong information results in wrong estimates, and ultimately wrong decisions.

4. The use of Breakeven analysis is good for short term time horizon in planning and decision making, a period of 1 to 5years is recommended, using Break even to predict for a long time horizon may not be encouraged, due to changes in cost behaviour which would definitely occur.

\section{Contribution to Knowledge:}

In the course of carrying out this work, rigorous study was done, and in order to summary the major findings during the course of the work, the researcher came up with a simple model pictured below, to give a quick understanding of the basic idea of Breakeven analysis.

Source: Researcher's Model, 2017.

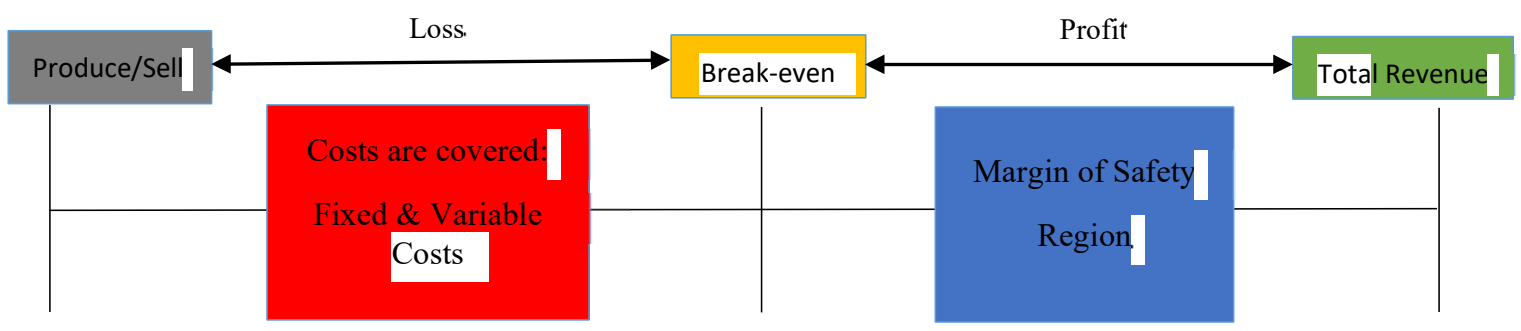

\section{References}

Abdulrasheed, I. B. (2010). An appraisal of Break even analysis to Business Managers in Decision Making. Adamawa Journal of Management and Decision Analysis.

Adeniyi, A. (2001). An insight into Management Accounting. Value Analysis Publishers. Adeniji, A. A. (2004). An insight to management accounting. Lagos: Value Analysis Consult

Akintoye, I. R. (2004). Investment Decisions: Concepts, Analysis \& Management. Lagos: Unique Educational Publishers.

Breakeven Point (2009, December 30). Retrieved from Encyclopedia of Management: Enotes.com Inc.

Choo F. \& K. Tan (2011). An Income Statement Teaching Approach for Cost-Volume-Profit (CVP) Analysis by Using a Company's CVP Model, Journal of Accounting and $\quad$ Finance vol. 11(4) 2011 pp $23-$ 36

Dascher, P., Strawser, J., \& Strawser, R. (2003). Managerial Accounting. Sheridan Books. 
Drury, C. (2001). Management and Cost Accounting. Cengage Learning \& Higher Education.

Drury, C. (2005). Management and Cost Accounting. Cengage Learning.

Edmonds, Tsay, B., \& Edmonds, G. (2000). Fundamental Managerial Accounting Concepts. Mc Graw Hill.

Enyi E. P. (2012) Removing the Constraining Assumption of No Joint Products in Breakeven Analysis, American Journal Of Contemporary Research Vol. 2 No. 5 May 2012. Pp $204-209$

Hilton, R. W. (1994). Managerial Accounting. Mc Graw Hill Inc.

Isiaka B. \& Abdulrasheed A. (2010). An Appraisal of the Usefulness of Break even analysis to Business Managers in Decision Making, Adamawa Journal of Management and Decision Analysis

Lucey, T. (1999). Management Accounting. London: Letts Educational .

Lucey, T. (2000). Management Accounting . Gosport: Ashford Colour Press.

Ndaliman B.M. \& K. C. Bala (2007). Practical Limitations of Break-Even Theory Department of Mechanical Engineering, Federal University of Technology Minna, $\quad$ Nigeria 58-61 (Jul. 2007)

Nwachukwu, C.C. (2004). Management: Theory and practice.. Onitsha: Africana First Publishers Limited.

Powers, L. (1987). Break-even analysis with semi-fixed cost. Ind. Market Management. 